\title{
Resistance Exercise Increases the Capacity of Heme Biosynthesis More Than Aerobic Exercise in Rats
}

\author{
Tatsuhiro MAtsuo, ${ }^{1, *}$ Hiroo SuzuKI, ${ }^{1}$ and Masashige SuzukI ${ }^{2}$ \\ ${ }^{1}$ Faculty of Agriculture, Kagawa University, Ikenobe, Miki-cho, Kagawa 761-0795, Japan \\ ${ }^{2}$ Institute of Health and Sport Sciences, University of Tsukuba, \\ Tsukuba 305-8574, Japan
}

(Received June 25, 2000)

\begin{abstract}
Summary To evaluate the effects of voluntary resistance exercise and aerobic exercise on iron status in rats fed an iron-deficient diet $(5 \mathrm{mg} \mathrm{Fe} /$ $\mathrm{kg}$, ID) or rats fed a control diet $(35 \mathrm{mg} \mathrm{Fe} / \mathrm{kg}, \mathrm{CN})$, we trained female Wistar rats for 3 weeks to climb a wire-mesh tower $(\phi 20 \mathrm{~cm} \times 200 \mathrm{~cm}$, CLIMB) and to swim in a plastic pool $(\phi 50 \mathrm{~cm} \times 50 \mathrm{~cm}, S W I M)$. These animals were compared with sedentary (SED) rats. After the experimental period, the blood hemoglobin concentration, hematocrit, plasma iron, and transferrin saturation were significantly lower $(p<0.05)$ in the ID rats than in the $\mathrm{CN}$ rats; as was the content in the liver, spleen, heart, kidney, skeletal muscles, and carcass $(p<0.05)$. The activity of $\delta$-aminolevulinic acid dehydratase, the marker enzyme for heme biosynthesis, in bone marrow was significantly higher $(p<0.05)$ in the CLIMB group than in the SWIM group. These results suggest that resistance exercise increases heme biosynthesis more than aerobic exercise but that neither exercise improved severe iron deficiencies.
\end{abstract}

Key Words: resistance exercise, swimming exercise, iron deficiency, $\delta$-aminolevulinic acid dehydratase, heme biosynthesis

Iron deficiency continues to be a significant nutritional problem around in the world $[1,2]$. It has deleterious effects on work performance, immune function, sympathetical and endocrinal metabolism, and thermoregulatory performance [36]. Although the hematologic and functional consequences of iron deficiency have been classically ascribed to a dietary or pathologic origin [2], previous studies suggest that chronic exercise might detrimentally alter body iron physiology.

* To whom correspondence should be addressed. Faculty of Agriculture, Kagawa University, Ikenobe, Miki-cho, Kita-gun, Kagawa 761-0795, Japan (Tel: +81-87-891-3082; Fax: +81-87891-3021; E-mail: matsuo@ag.kagawa-u.ac.jp). 
Decreased hematocrit, hemoglobin and serum iron, and increased erythrocyte fragility, may occur in aerobic exercising individuals [7-10]. Thus far, animal studies $[11,12]$ that examined iron deficiency and aerobic exercise interactions demonstrated that exercise lessens the impact of moderate iron deficiency on essential body iron components, such as hemoglobin. Hisaoka and Shibuya [13] demonstrated that hemoglobin, hematocrit, and blood red cell volume were significantly higher in female swimming rats than in control rats. Tobin and Beard [14] reported that running failed to alter hemoglobin, hematocrit and red blood cell mass in iron-deficient and control rats.

On the other hand, studies on the effects of resistance exercise on body iron status are limited in number. We previously demonstrated that mild resistance exercise improved non-anemic iron deficiency without iron supplementation in young women [15]. However, the mechanism of the effects of resistance exercise on iron metabolism is not clear.

Recently, we designed a new voluntary resistance training model, in which rats climbed a vertical tower [16]. The purpose of the present study was to determine whether resistance exercise induces an improvement of essential body iron components in iron-deficient rats and, if so, to determine how the increase in $\delta$-aminolevulinic acid dehydratase (ALAD) activity in bone marrow, a marker enzyme of mitochondrial heme biosynthesis, compares with that found with aerobic exercise.

\section{MATERIALS AND METHODS}

All procedures involving animals were approved by the Experimental Animal Care Committee of Kagawa University.

Animals and experimental design. Twenty-four female Wistar rats (3 weeks old) were obtained from Japan SLC, Inc. (Shizuoka, Japan). The rats were fed CE-2, commercial rodent diet (CLEA Japan, Tokyo), and given water ad libitum through 4 weeks of age. All animals were individually housed in an animal room at $24 \pm 1^{\circ} \mathrm{C}$, with lights on from 8 a.m. to 8 p.m. Half of the animals were assigned to the AIN-76 diet $[17,18]$, with less than $5 \mathrm{mg} \mathrm{Fe} / \mathrm{kg}$ (iron deficiency, ID), and the other half were assigned to an identical diet with $35 \mathrm{mg} \mathrm{Fe} / \mathrm{kg}$ (control, $\mathrm{CN}$ ). The ID and $\mathrm{CN}$ rats were each randomly divided into 3 subgroups, sedentary (SED), swimming exercise (SWIM), and climbing exercise (CLIMB) groups. Each group of rats ( $n=4$ /group) was given free access to the ID or CN diet, and water for 21 days. After the 21-day experimental period, the rats were fasted overnight and killed by decapitation at 10 a.m. under light ether anesthesia. Liver, spleen, heart, kidney, and skeletal muscles were quickly removed and stored at $-40^{\circ} \mathrm{C}$ until analysis could be performed. Carcass samples were obtained by removing the head, digestive tracts, lungs, testes, and abdominal adipose tissues, and stored at $-20^{\circ} \mathrm{C}$ until analyzed.

Exercise training. The voluntary resistance training model, CLIMB [16], 
was a modification of that described by Yarasheki et al. [19] and Duncan et al. $[20]$. Rats of the CLIMB group were housed in metal cages containing wire-mesh towers $(\phi 20 \mathrm{~cm} \times 200 \mathrm{~cm})$ with water bottles set on the top of the tower [16]. On the other hand, the rats of the SWIM group were trained from 8 a.m. to 9 a.m. every day in a plastic pool $(\phi 50-50 \mathrm{~cm})$ with water maintained at $33-35^{\circ} \mathrm{C}$. The swimming exercise was performed in the manner described previously $[21,22]$. All rats were rested for $24 \mathrm{~h}$ in their individual cages before sacrifice.

Blood and plasma analysis. Blood hemoglobin concentrations were determined colorimetrically by using a hemoglobin B-Test kit purchased from Wako Pure Chemical Industries (Osaka, Japan). The hematocrit was measured by centrifugation of blood collected into heparinized microcapillary tubes. Plasma iron concentration and total iron binding capacity (TIBC) were determined by the method prescribed by the International Nutritional Anemia Consultative Group [23]. Transferrin saturation was calculated by plasma iron concentration and TIBC [21].

Tissue and carcass iron. Carcass samples were prepared by the method of Mickelsen and Anderson [24]. Iron contents in the liver, spleen, heart, kidney, soleus muscle, white and red gastrocnemius muscles, and carcass were measured after acid hydrolysis by using an atomic absorption spectrophotometer (Model Z-5000, Hitachi, Tokyo, Japan).

Enzyme assay. ALAD activity in the bone marrow was measured by the method of Sassa [25], with the modification that Ehrlich's reagent was made as reported by Tomokuni [26]. Briefly, about $30 \mathrm{mg}$ of bone marrow was obtained from the femur and homogenized in a micro homogenizer (ULTRA-TURRAX, IKA Co., Staufen, Germany) at $0-4^{\circ} \mathrm{C}$ containing $270 \mu \mathrm{l}$ of $0.1 \mathrm{M}$ potassium phosphate buffer $(\mathrm{pH} 6.4)$. Part of the homogenate $(100 \mu 1)$ was transferred to a $1.5-\mathrm{ml}$ tube, and $250 \mu 1$ of $0.1 \mathrm{M}$ potassium phosphate buffer containing $10 \mathrm{~mm}$ $\delta$-aminolevulinic acid was added. After incubation for $30 \mathrm{~min}$ at $37^{\circ} \mathrm{C}$, the reaction was terminated by the addition of $250 \mu \mathrm{l}$ of $10 \%$ trichloroacetic acid. The precipitate was centrifuged at $15,000 \times g$ for $10 \mathrm{~min}$. A $0.5-\mathrm{ml}$ volume of the supernatant was removed into another tube, and $0.5 \mathrm{ml}$ of modified Ehrlich's reagent was added. After 40-60 min, the color solution absorbance was determined at $553 \mathrm{~nm}$ vs. the blank containing $0.5 \mathrm{ml}$ of $0.1 \mathrm{M}$ potassium phosphate buffer and $0.5 \mathrm{ml}$ of modified Ehrlich's reagent. The ALAD activity was calculated as follow: absorbance $\times 2 \times 120 \times 2 / 6.2(\mu \mathrm{mol} / \mathrm{h} / \mathrm{g}$ tissue) $(2$, conversion factor from porphobilinogen to $\delta$-aminolevulinic acid ; 120 , dilution factor ; 2 , incubation time ; 6.2 , extinction coefficient in $\mathrm{ml} / \mu \mathrm{mol} \cdot \mathrm{cm}$ ). Protein content in the reaction mixture was determined by the method reported by Lowry et al. [27].

The activities of citrate synthase in the heart and plantaris muscle were determined by the method described by Srere [28] to establish whether the training protocol had any effect on aerobic metabolism. One unit of the citrate synthase catalyzed the formation of $1 \mu \mathrm{mol}$ free $\mathrm{CoA} / \mathrm{min}$ [28].

Statistics. Data were expressed as means \pm SE. All data were analyzed by a

Vol. 29, 2000 
factorial analysis of variance (ANOVA) and Fisher's PLSD tests. Differences were considered statistically significant at $p<0.05$.

\section{RESULTS}

Body weight, food intake, and food efficiency

Body weight changes over 21 days and body weight gain are shown in Fig. 1. Exercise training lowered body weight gain in both ID and $\mathrm{CN}$ rats. In ID rats, the body weight gain was significantly lower $(p<0.05)$ in the CLIMB group than in the SED group (Fig. 1). Food intake was approximately the same in all experimental groups $(284 \pm 12,271 \pm 8,296 \pm 4,270 \pm 8,273 \pm 10$, and $280 \pm 2 \mathrm{~g} / 21$ days for CN-SED, CN-SWIM, CN-CLIMB, ID-SED, ID-SWIM, and ID-CLIMB groups, respectively). Food efficiency was significantly lower $(p<0.05)$ in the SWIM and CLIMB groups than in the SED group for both ID and CN rats $(186 \pm 5,178 \pm$ $1,166 \pm 3,188 \pm 7,168 \pm 6$, and $153 \pm 3 \mathrm{mg}$ body weight/g for CN-SED, CN-SWIM, CN-CLIMB, ID-SED, ID-SWIM, and ID-CLIMB groups, respectively).

\section{Hemoglobin, hematocrit, plasma iron, and transferrin saturation}

The results of hemoglobin, hematocrit, plasma iron, and transferrin saturation measurements are shown in Table 1. All components were significantly lower $(p<$ 0.05 ) in the ID rats than in the CN rats for SED, SWIM, and CLIMB groups. However, neither exercise affected the iron status of the ID or $\mathrm{CN}$ rats.

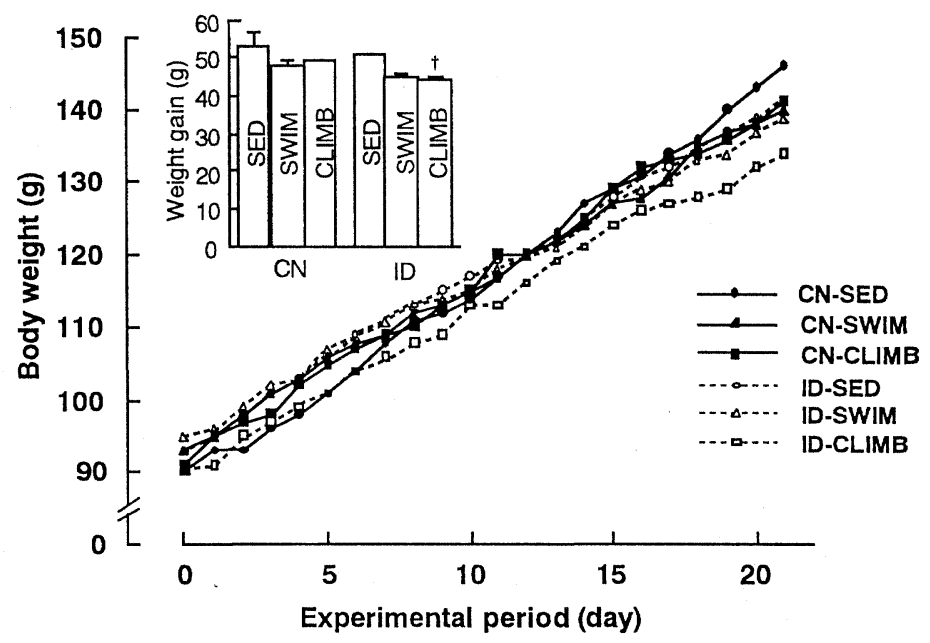

Fig. 1. Body weight changes over 21 days and weight gains of sedentary and exercised rats. Values are means and SE (weight gain graph only) for 4 rats. ${ }^{\dagger}$ Statistically significant difference from the sedentary group $(p<0.05$, ANOVA and Fisher's PLSD tests). ANOVA indicated significant $(p<0.05)$ main effects of exercise. 
Table 1. Effects of exercise and iron deficiency on hemoglobin, hematocrit, plasma iron, and transferrin saturation in rats. ${ }^{a}$

\begin{tabular}{|c|c|c|c|c|c|}
\hline Group $^{b}$ & $n$ & $\begin{array}{l}\text { Hemoglobin } \\
(\mathrm{mg} / 100 \mathrm{ml})\end{array}$ & $\begin{array}{c}\text { Hematocrit } \\
(\%)\end{array}$ & $\begin{array}{l}\text { Plasma iron } \\
(\mu \mathrm{g} / \mathrm{ml})\end{array}$ & $\begin{array}{c}\text { Transferrin } \\
\text { saturation } \\
(\%)\end{array}$ \\
\hline CN-SED & 4 & $13.9 \pm 0.6$ & $43.5 \pm 0.7$ & $3.23 \pm 0.36$ & $61.0 \pm 3.9$ \\
\hline CN-SWIM & 4 & $13.2 \pm 0.4$ & $42.4 \pm 1.3$ & $2.90 \pm 0.25$ & $52.1 \pm 4.9$ \\
\hline CN-CLIMB & 4 & $13.7 \pm 0.7$ & $42.9 \pm 0.7$ & $2.64 \pm 0.22$ & $49.6 \pm 4.8$ \\
\hline ID-SED & 4 & $10.3 \pm 0.5^{*}$ & $33.8 \pm 0.7^{*}$ & $0.79 \pm 0.07^{*}$ & $10.0 \pm 3.2 *$ \\
\hline ID-SWIM & 4 & $10.0 \pm 0.5^{*}$ & $32.6 \pm 1.3^{*}$ & $0.74 \pm 0.13^{*}$ & $12.7 \pm 2.1^{*}$ \\
\hline ID-CLIMB & 4 & $10.4 \pm 0.5^{*}$ & $33.1 \pm 1.2^{*}$ & $0.81 \pm 0.13^{*}$ & $14.9 \pm 3.5^{*}$ \\
\hline
\end{tabular}

${ }^{a}$ Values are means \pm SE for 4 rats. ${ }^{*}$ Statistically significant difference from the corresponding control group ( $p<0.05$, ANOVA and Fisher's PLSD tests). ANOVA indicated significant $(p<0.05)$ main effects of diet for all variables. ${ }^{b} \mathrm{CN}$, control; ID, iron deficiency; SED, sedentary; SWIM, swimming exercise; CLIMB, climbing exercise.

Table 2. Effects of exercise and iron deficiency on various tissue and carcass iron contents in rats $^{a}$

\begin{tabular}{|c|c|c|c|c|c|}
\hline Group $^{b}$ & $n$ & $\begin{array}{c}\text { Liver } \\
(\mu \mathrm{g} / \mathrm{g})\end{array}$ & $\begin{array}{l}\text { Spleen } \\
(\mu \mathrm{g} / \mathrm{g})\end{array}$ & $\begin{array}{l}\text { Kidney } \\
(\mu \mathrm{g} / \mathrm{g})\end{array}$ & $\begin{array}{l}\text { Heart } \\
(\mu \mathrm{g} / \mathrm{g})\end{array}$ \\
\hline CN-SED & 4 & $104.9 \pm 5.0$ & $195.2 \pm 8.7$ & $49.3 \pm 4.2$ & $76.0 \pm 1.2$ \\
\hline CN-SWIM & 4 & $98.4 \pm 4.6$ & $203.5 \pm 13.3$ & $47.3 \pm 2.6$ & $75.0 \pm 2.5$ \\
\hline CN-CLIMB & 4 & $97.9 \pm 5.2$ & $195.1 \pm 8.8$ & $41.7 \pm 1.8$ & $69.9 \pm 3.2$ \\
\hline ID-SED & 4 & $30.9 \pm 0.5^{*}$ & $118.4 \pm 8.6^{*}$ & $30.6 \pm 1.2^{*}$ & $58.8 \pm 2.3^{*}$ \\
\hline ID-SWIM & 4 & $32.6 \pm 1.4^{*}$ & $120.0 \pm 5.5^{*}$ & $29.1 \pm 0.7^{*}$ & $53.8 \pm 2.1^{*}$ \\
\hline ID-CLIMB & 4 & $32.0 \pm 1.3^{*}$ & $134.2 \pm 7.4^{*}$ & $31.6 \pm 1.2^{*}$ & $58.8 \pm 2.7^{*}$ \\
\hline Group & $n$ & $\begin{array}{l}\text { Soleus } \\
(\mu \mathrm{g} / \mathrm{g})\end{array}$ & $\begin{array}{c}\text { Red } \\
\text { gastrocnemius } \\
(\mu \mathrm{g} / \mathrm{g})\end{array}$ & $\begin{array}{c}\text { White } \\
\text { gastrocnemius } \\
(\mu \mathrm{g} / \mathrm{g})\end{array}$ & $\begin{array}{c}\text { Carcass } \\
(\mu \mathrm{g} / \mathrm{g})\end{array}$ \\
\hline CN-SED & 4 & $23.9 \pm 0.7$ & $18.5 \pm 0.5$ & $11.4 \pm 0.8$ & $12.4 \pm 0.6$ \\
\hline CN-SWIM & 4 & $24.3 \pm 0.5$ & $18.1 \pm 0.5$ & $10.5 \pm 1.3$ & $12.3 \pm 0.4$ \\
\hline CN-CLIMB & 4 & $24.6 \pm 0.4$ & $17.9 \pm 0.6$ & $10.4 \pm 0.8$ & $13.1 \pm 0.2$ \\
\hline ID-SED & 4 & $17.7 \pm 1.3^{*}$ & $12.3 \pm 0.5^{*}$ & $8.4 \pm 0.7^{*}$ & $7.5 \pm 0.3^{*}$ \\
\hline ID-SWIM & 4 & $19.6 \pm 0.7^{*}$ & $12.2 \pm 0.4^{*}$ & $6.8 \pm 0.4^{*}$ & $7.6 \pm 0.6^{*}$ \\
\hline ID-CLIMB & 4 & $22.7 \pm 1.6$ & $13.5 \pm 0.7^{*}$ & $7.9 \pm 0.3^{*}$ & $8.4 \pm 0.7^{*}$ \\
\hline
\end{tabular}

${ }^{a}$ Values are means \pm SE for 4 rats. * Statistically significant difference from the corresponding control group ( $p<0.05$, ANOVA and Fisher's PLSD tests). ANOVA indicated significant $(p<0.05)$ main effects of diet for all variables. ${ }^{b} \mathrm{CN}$, control; ID, iron deficiency; SED, sedentary; SWIM, swimming exercise; CLIMB, climbing exercise.

\section{Tissue and carcass iron contents}

The iron content in the liver, spleen, heart, kidney, soleus muscle, red and white gastrocnemius muscle, and carcass was significantly lower $(p<0.05)$ in the ID rats than in the $\mathrm{CN}$ rats (Table 2). However, neither exercise affected the iron status of the ID or CN rats except for the soleus iron content in the ID-CLIMB group (Table 2). Liver iron was more strongly affected by the ID diet $(67 \%$ 


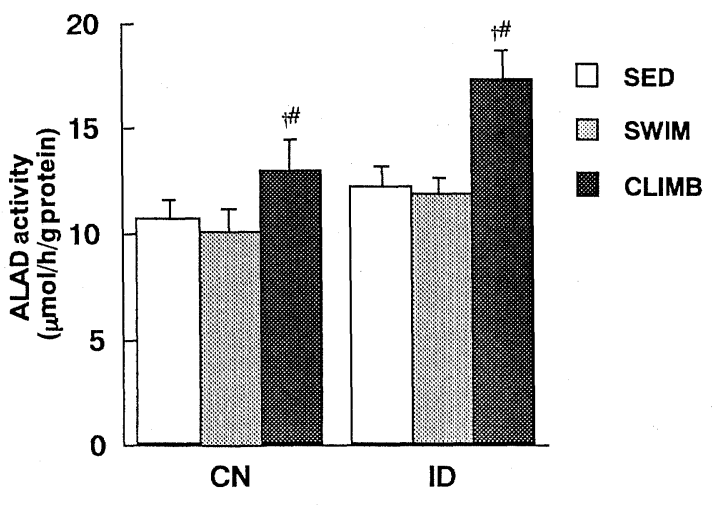

Fig. 2. Effects of exercise and iron deficiency on bone marrow $\delta$-aminolevulinic acid dehydratase activity in rats. Values are means and SE for 4 rats. ${ }^{\dagger}$ Statistically significant difference from the sedentary-group value. \#Statistically significant difference from the swimming exercise-group value ( $p<0.05$, ANOVA and Fisher's PLSD tests). ANOVA indicated significant $(p<0.05)$ main effects of exercise. CN, control; ID, iron deficiency; SED, sedentary; SWIM, swimming exercise; CLIMB, climbing exercise; ALAD, $\delta$-aminolevulinic acid dehydratase.

Table 3. Effects of exercise and iron deficiency on citrate synthase activity in plantaris muscle and heart of rats $^{a}$

\begin{tabular}{lccc}
\hline Group $^{b}$ & $n$ & $\begin{array}{c}\text { Plantaris } \\
\text { (U/g tissue })\end{array}$ & $\begin{array}{c}\text { Heart } \\
\text { (U/g tissue })\end{array}$ \\
\hline CN-SED & 4 & $2.9 \pm 0.5$ & $3.21 \pm 0.4$ \\
CN-SWIM & 4 & $2.8 \pm 1.0$ & $10.5 \pm 1.1$ \\
CN-CLIMB & 4 & $6.7 \pm 0.9$ & $9.4 \pm 1.3$ \\
ID-SED & 4 & $2.4 \pm 0.9$ & $5.5 \pm 1.6$ \\
ID-SWIM & 4 & $3.4 \pm 0.9$ & $7.5 \pm 0.4$ \\
ID-CLIMB & 4 & $4.9 \pm 0.8$ & $10.7 \pm 1.4$ \\
\hline
\end{tabular}

${ }^{a}$ Values are means \pm SE for 4 rats. Statistically significant difference from the sedentary. \#Statistically significant difference from the swimming exercise group $(p<0.05$, ANOVA and Fisher's PLSD tests). ANOVA indicated significant $(p<0.05)$ main effects of exercise for all variables. ${ }^{b} \mathrm{CN}$, control; ID, iron deficiency; SED, sedentary; SWIM, swimming exercise; CLIMB, climbing exercise.

decreases for both SWIM and CLIMB groups) than the iron in other tissues.

\section{Enzyme activity}

The climbing exercise increased but swimming exercise did not increase, bone marrow ALAD activity in both ID and CN groups (Fig. 2). The bone marrow ALAD activity was significantly higher $(p<0.05)$ in the CLIMB group than in the SED and SWIM groups (Fig. 2). Citrate synthase activities in both plantaris muscle and heart were increased by exercise training (Table 3). Climbing exercise 
by rats resulted in a significant increase $(p<0.05)$ in citrate synthase activity in both the plantaris muscle (104 and 131\% for ID and CN groups, respectively) and heart (95 and 193\% for ID and CN groups, respectively). Swimming exercise significantly $(p<0.05)$ increased the activity of heart citrate synthase in the $\mathrm{CN}$ rats, but did not activate plantaris citrate synthase (Table 3 ).

\section{DISCUSSION}

This study demonstrated that resistance exercise (CLIMB) increased the capacity of heme biosynthesis in the bone marrow more than did aerobic exercise (SWIM). These results suggest that the capacity for heme biosynthesis may be dependent on resistant loads to the animal body. Considerable evidence indicates that ALAD, the enzyme in the porphyrin pathway, is a marker enzyme for heme biosynthesis [29]. Thus, increases in the activity of this enzyme in the CLIMB rat bone marrow have been linked to accelerated heme production. Hemoglobin is dependent on heme synthesis in the bone marrow since iron-containing porphyrin constitutes the ring structure to which the hemoglobin is conjugated with apoprotein. Therefore, we considered it likely that the heme pathway would be accelerated when exercise-induced increases in the hemoglobin concentration could be expected. However, our results showed no exercise-induced effects on the capacity for heme biosynthesis as reflected in hemoglobin production as well as on other blood components. Tobin and Beard [14] suggested that training in irondeficient animals was characterized by a higher percentage of ${ }^{59} \mathrm{Fe}$ associated with red cells than that for iron-deficient sedentary rats within $1 \mathrm{~h}$ after intravenous injection of ${ }^{59} \mathrm{Fe}$. But they failed to show any improvement in the blood hemoglobin level in iron-deficient trained rats. Franzone et al. [30] determined that the blood red cell mass and hemoglobin were the initial sites of plasma iron clearance. A reduction in plasma iron circulation caused by severe iron deficiency may void exercise-induced alterations in the capacity for heme biosynthesis.

In this study, the iron content in several tissues was significantly lower in the ID rats, and neither exercise affected the iron status of the ID or CN rats except for the soleus iron content in ID-CLIMB group. Liver iron was more severely reduced by the ID diet than the iron in other tissues. These findings are consistent with the fact that the liver is the main control site for plasma iron circulation [31]. Borel et al. [32] reported that as the dietary iron intake was increased above $11 \mathrm{mg} \mathrm{Fe} /$ $\mathrm{kg}$ diet, the liver iron concentration steadily increased, and the hemoglobin concentration was maintained at normal levels. Siimes et al. [33] determined that a dietary iron intake of less than $25 \mathrm{mg} \mathrm{Fe} / \mathrm{kg}$ diet resulted in hemoglobin concentrations of $12 \mathrm{mg} / 100 \mathrm{ml}$ or below. From these points of view, the dietary iron level in the ID diet (less than $5 \mathrm{mg} \mathrm{Fe} / \mathrm{kg}$ diet) that we used in this study might have been too low to examine the effects of exercise on body iron status.

Previous studies $[34,35]$ showed that iron deficiency did not suppress animal growth during a 12-week experimental period. We also failed to observe a signifi-

Vol. 29, 2000 
cant depression in body weight attributable to iron deficiency. However, both exercises depressed body weight gain in both dietary treatment groups, with the iron-deficient CLIMB rats showing the greatest attenuation of growth (12.8\%). On the other hand, food intake was at the same level in all experimental groups. These data demonstrate that fat mass is reduced in ID-CLIMB rats compared to ID-SED rats, since muscle mass and carcass protein content did not differ among the 6 groups (data not shown). Tobin and Beard [14] reported that both iron deficiency and running significantly increased resting oxygen consumption, as an index of resting energy expenditure, $48 \mathrm{~h}$ postexercise in rats. Consequently, fat mass was significantly lower in iron-deficient exercised rats than in iron-deficient sedentary rats. Our present study supports the results of Tobin and Beard.

Citrate synthase activities in the plantaris muscle and heart were increased by exercise training. CLIMB training by rats resulted in a significant increase in citrate synthase activity in both the plantaris muscle and heart. These results are in agreement with our previous findings [16]. On the other hand, swimming significantly increased the activity of heart citrate synthase in the $\mathrm{CN}$ rats, but did not activate plantaris citrate synthase. Voluntary swimming exercise may increase the aerobic capacity of the heart prior to that of the skeletal muscles.

In conclusion, our study suggests that resistance exercise increases the capacity of heme biosynthesis in the bone marrow as compared with aerobic exercise. However, resistance exercise did not improve severe iron deficiencies. Further study using rats at other iron-deficiency levels will be required to clarify the details concerning the effects of resistance exercise on iron-deficiency anemia.

\section{REFERENCES}

1. Beard, J.L., and Finch, C.L. (1985): Iron deficiency, in Iron Fortification of Food, Academic Press, New York, NY, pp. 3-16.

2. Finch, C.A., and Huebers, M.D. (1982): Perspectives in iron metabolism. N. Engl. J. Med., 25, $1520-1528$.

3. Dallman, P.R. (1986): Biochemical basis for the manifestations of iron deficiency. Annu. Rev. Nutr., 6, 13-40.

4. Dallman, P.R. (1982): Manifestations of iron deficiency. Semin. Hematol., 19, 19-30.

5. Scrimshaw, N.S. (1984): Functional consequences of iron deficiency in human populations. J. Nutr. Sci. Vitaminol., 30, 47-63.

6. Cook, J.D., and Lynch, S.R. (1984): The liabilities of iron deficiency. Blood, 68, 803-809.

7. Dressendorfer, R.H., Wade, C.E., and Amsterdman, E.A. (1981): Development of a pseudoanemia in marathon runners during a 20-day road race. $J A M A, \mathbf{2 4 6}, 1215-1218$.

8. Wijn, J.F., De Jongeste, J.L., Monsterd, W., and Willebrand, D. (1971): Hemoglobin, packed cell volume, and iron binding capacity of selected athletes during training. Nutr. Metab., 13, 129-139.

9. Ehn, L., Carlmark, B., and Hoglund, S. (1977): Iron status in athletes involved in intense physical activity. Med. Sci. Sports Exerc., 12, 61-64.

10. Radomski, M.W., Sabiston, B.H., and Isoard, P. (1980): Development of sports anemia in physically fit men after daily sustained submaximal exercise. Aviat. Space Environ. Med., 51, 41-45.

11. Perkkio, M.V., Jansson, L.T., Henderson, H., Refino, C.J., Brooks, G.A., and Dallman, P.R. (1985): Work performance in the iron deficient rat: Improved endurance with exercise 
training. Am. J. Physiol., 249, E306-E311.

12. Willis, W.T., Brooks, G.A., Henderson, S.A., and Dallman, P.R. (1987): Effects of iron deficiency and training on mitochondrial enzymes in skeletal muscle. J. Appl. Physiol., 62, 2442-2446.

13. Hisaoka, F., and Shibuya, M. (1983): Effects of training on hematological values (hemoglobin, hematocrit and plasma volume) in growing male and female rats. J. Jpn. Soc. Nutr. Food. Sci., 36, 141-149.

14. Tobin, B.W., and Beard, J.L. (1989): Interactions of iron deficiency and exercise training in male Sprague-Dawley rats: ferrokinetics and hematology. J. Nutr., 119, 1340-1347.

15. Matsuo, T., and Suzuki, M. (1998): Dumbbell exercise improved iron deficient stores in young women without iron supplementation. FASEB J., 12, A849.

16. Matsuo, T., Mizushima, Y., Fujie, M., Suzuki, M. (1999): Effect of voluntary resistance exercise on mitochondrial heme biosynthesis in rat liver. J. Clin. Biochem. Nutr., 27, 151159.

17. American Institute of Nutrition (1977): Report of the American Institute of Nutrition ad hoc committee on standards for nutritional studies. J. Nutr., 107, 1340-1348.

18. American Institute of Nutrition (1980): Second report of the ad hoc committee on standards for nutritional studies. J. Nutr., 110, 1726.

19. Yarasheki, K.E., Lemon, P.W., and Gilloteaux, J. (1990): Effect of heavy resistance exercise training on muscle fiber composition in young rats. J. Appl. Physiol., 69, 434-437.

20. Duncan, N.D., Williams, D.A., and Lynch, G.S. (1998): Adaptations in rat skeletal muscle following long-term resistance exercise training. Eur. J. Appl. Physiol., 77, 372-378.

21. Saitoh, S., Shimomura, Y., Tasaki, Y., and Suzuki, M. (1992): Effect of short-term exercise training on muscle glycogen in resting conditions in rats fed a high fat diet. Eur. J. Appl. Physiol., 64, 62-67.

22. Saitoh, S., Matsuo, T., and Suzuki, M. (1993): The effects of a high carbohydrate diet on postprandial energy expenditure during exercise in rats. Eur. J. Appl. Physiol., 66, 445-450.

23. International Nutritional Anemia Consultative Group (1985): Measurements of Iron Status, The Nutrition Foundation Inc., Washington DC, pp. 12-22.

24. Mickelsen, O., and Anderson, A.A. (1959): A method for preparing intact animals for carcass analysis. J. Lab. Clin. Med., 53, 282-290.

25. Sassa, S. (1982): Delta-aminolevulinic acid dehydratase assay. Enzyme, 28, 133-145.

26. Tomokuni, K. (1974): New method for determination of aminolevulinate dehydratase activity of human erythrocytes as an index of lead exposure. Clin. Chem., 20, 1287-1291.

27. Lowry, O.H., Rosebrough, N.J., Farr, A.L., and Randall, R.J. (1951): Protein measurement with the folin phenol reagent. J. Biol. Chem., 193, 265-275.

28. Srere, P.A. (1969): Citrate synthase. Methods Enzymol., 13, 3-5.

29. Finelli, V.N., Murthy, L., Oeirano, W.B., and Petering, H.G. (1974): $\delta$-Aminolevulinate dehydratase, a zinc dependent enzyme. Biochem. Biophys. Res. Commun., 60, 1418-1424.

30. Franzone, P.C., Paganuzzi, A., and Stefanelli, M. (1982): A mathematical model of iron metabolism. J. Math. Biol, 15, 173-201.

31. Torrance, J.D., and Bothwell, T.H. (1980): Tissue iron stores, in Methods in Hematology, ed. by Cook, J.D., Churchill Livingstone, New York, NY, pp. 90-115.

32. Borel, M.J., Smith, S.H., Brigham, D.E., and Beard, J.L. (1991): The impact of varying degrees of iron nutriture on several functional consequences of iron deficiency in rats. $J$. Nutr., 121, 729-736.

33. Siimes, M.A., Refino, C., and Dallman, P.R. (1980): Manifestation of iron deficiency at various levels of dietary iron intake. Am. J. Clin. Nutr., 33, 570-574.

34. Beard, J.L., and Tobin, B.W. (1987): Norepinephrine turnover and energetic efficiency in iron deficiency anemia. Proc. Soc. Exp. Biol. Med., 184, 337-344.

35. Beard, J.L., Heubers, E., and Finch, C.A. (1984): Protein depletion and iron deprivation. J. Nutr., 114, 1396-1401. 